\title{
A comparison of sacral neuromodulation vs. transvaginal electrical stimulation for the treatment of refractory overactive bladder: the impact on quality of life, body image, sexual function, and emotional well-being
}

\author{
Valentina Lucia La Rosa ${ }^{1}$, Alessio Platania², Michał Ciebiera ${ }^{3}$, Simone Garzon $^{4}$, Robert Jędra ${ }^{3}$, \\ Marco Ponta 5 , Salvatore Butticè ${ }^{6}$ \\ ${ }^{1}$ Unit of Psychodiagnostics and Clinical Psychology, University of Catania, Catania, Italy \\ ${ }^{2}$ James Street Family Practice, Louth, UK \\ ${ }^{3}$ Second Department of Obstetrics and Gynaecology, The Centre of Postgraduate Medical Education, Warsaw, Poland \\ ${ }^{4}$ Department of Obstetrics and Gynaecology, "Filippo Del Ponte” Hospital, University of Insubria, Varese, Italy \\ ${ }^{5}$ Department of Neurosciences and Reproductive and Odontostomatological Sciences, University of Naples Federico II, Naples, Italy \\ ${ }^{6}$ Department of Urology, San Giovanni di Dio Hospital, Agrigento, Italy
}

\begin{abstract}
Overactive bladder syndrome $(\mathrm{OAB})$ is defined by the presence of urinary urgency, with or without urge incontinence, usually accompanied by an increase in urinary frequency and nocturia in the absence of urinary tract infections (UTI) or other diseases. The overall prevalence of OAB symptoms in the female population is reported to be $16.6 \%$ and increases with advancing age and menopause. The aetiology of OAB is not fully understood and is likely to affect a heterogeneous population of patients due to changes to their central and peripheral nervous systems. Although OAB is frequently associated with female sexual dysfunction (FSD), its real impact on sexual function in women has been evaluated only in a few studies. The first line of treatment for $O A B$ includes behavioural modification and physical therapy, either as monotherapies or in combination. Many patients who have not had success in managing their symptoms with more conservative therapies may decide to resort to third-line treatments for refractory $\mathrm{OAB}$. These treatments include neuromodulation therapies, particularly transvaginal electrical stimulation (TES) and sacral neuromodulation (SN). The aim of this short commentary is to provide an overview of the effectiveness of these treatments and of their impact on quality of life, body image, sexual function, and emotional well-being.
\end{abstract}

Key words: overactive bladder syndrome, transvaginal electrical stimulation, sacral neuromodulation, menopause, quality of life, sexual function.

Overactive bladder syndrome $(\mathrm{OAB})$ was first described in 1996 and is defined by the presence of urinary urgency, with or without urge incontinence, usually accompanied by an increase in urinary frequency and nocturia in the absence of urinary tract infections (UTI) or other diseases [1-3].

Symptoms of $\mathrm{OAB}$ are also common to interstitial cystitis/painful bladder syndrome (IC/PBS) [4]. However, we can distinguish these diseases by the presence of urinary incontinence in patients with $O A B$ and pelvic pain in patients with IC/PBS $[4,5]$. Furthermore, OAB often occurs concomitantly with pelvic organ prolapse (POP) with a significant impairment of the quality of life of women affected [6-9]. It has been underlined that OAB symptoms improve after treatment of POP [10-17].
In addition, there seems to be a significant association between anterior and/or fundal leiomyoma and $\mathrm{OAB}$. For this reason, the presence of uterine leiomyoma should be taken into account in women affected by overactive bladder [18-21].

Bladder dysfunctions are also common after radical hysterectomy and radiotherapy for the treatment of gynaecological cancer [22-27]. Therefore, urinary symptoms should always be evaluated in cancer patients [27, 28].

Recently, a possible relationship between postpartum depression and symptoms of overactive bladder in postpartum women was hypothesised. Postpartum depression is a common complication of childbirth, and a number of studies have underlined a link between 
this condition and urinary symptoms [29-31]. Although it is difficult to establish the cause and/or effect relationship between the two conditions, the simultaneous presence of depression and urinary incontinence is associated with a worsening quality of life in affected women $[30,31]$.

The aetiology of OAB is not fully understood and is likely to affect a heterogeneous population of patients due to changes to their central and peripheral nervous systems [32]. The overall prevalence of OAB symptoms in the female population is reported to be $16.6 \%$ and increases with advancing age and menopause [33-36]. In this regard, the signs of menopause may be closely associated with a higher prevalence of $O A B$ and more severe symptoms [37, 38]. Furthermore, many women in menopausal age who suffer from this condition wait for years before undergoing treatment because of the lack of knowledge and shame associated with these symptoms [39].

The pathophysiology of OAB is complex and incompletely understood. The detrusor muscle is activated by the parasympathetic nervous system through the nerves originating at S2, S3, and S4 level [40]. The impulse is transmitted through acetylcholine (ACh), which acts a mediator on the muscarinic receptors, namely its action on the M3 subtype is the main cause for the contraction of the muscle tissue of the bladder. However, recent research has shown the role of the urothelium and the suburothelium in the perception of sensorial stimuli, and numerous pathological variations of expressed receptors have been reported in sufferers with OAB [41].

Several studies have underlined that OAB drastically reduces quality of life because of its negative influence on many aspects of patients' lives, including social, physical, and psychological well-being, and work productivity [42-45]. Moreover, both sexual desire and the capacity to reach an orgasm through penetration are impaired in female patients with $O A B$, thus affecting their sexual health $[46,47]$. Not surprisingly, many papers have reported that urinary symptoms can cause a huge psychological burden, likely to affect mental and sexual health through the production of negative emotions [47-52]. Although $O A B$ is frequently associated with female sexual dysfunction (FSD), its real impact on sexual function in women has been evaluated only in a few studies [42, 45-56]. In this regard, one of the most frequently used questionnaires in the literature to evaluate sexual dysfunctions related to different diseases is the Female Sexual Function Index (FSFI) [5760]. Data obtained through the use of this instrument underline that much more women with OAB report sexual dysfunction than the general, healthy female population without urinary symptoms [54, 55]. Moreover, in postmenopausal women, there is an association between severity of OAB symptoms and worsening sexu- al function, mainly in the domains of arousal, lubrication, orgasm, and pain [47, 61-64]. In this regard, the studies by Zhu et al. [38] and Hakimi et al. [39] confirm that women in menopausal age with $O A B$ report lower scores in all sub-domains of sexual function than women who do not suffer from OAB. Furthermore, OAB is associated with a reduced frequency of sexual intercourse during menopause [39].

Nevertheless, further studies on this topic are needed in order to better understand the effects of $O A B$ symptoms on sexual function and to improve sexual health in the affected women.

The first line of treatment for $O A B$ includes behavioural modification and physical therapy, either as monotherapies or in combination [65, 66]. First-line medical therapies are usually associated with a secondline of treatment of anticholinergics and $\beta-3$ agonists, before potentially considering invasive surgical treatments such as urinary diversion [66]. However, these medications are often characterised by lack of efficacy, poor compliance, low patient satisfaction, and side effects [67-69]. For these reasons, many patients who have not had success in managing their symptoms with more conservative therapies may decide to resort to third-line treatments for refractory OAB [70]. These treatments include neuromodulation therapies, particularly transvaginal electrical stimulation (TES) and sacral neuromodulation (SN) $[67,69,70]$.

TES is a conservative treatment option, described more than 40 years ago, which allows the use of a surgical approach later, if necessary [71, 72]. With TES, after attaching a sensor with electrodes in the vagina, the muscles of the pelvic floor are activated through a painless electric current [73, 74]. Different frequencies result in different outcomes. Pelvic floor muscles (PFMs) can be activated with frequencies between 35 and $40 \mathrm{~Hz}$, while at $5-10 \mathrm{~Hz}$ the effects spread also to the detrusor muscle. Based on results from randomised clinical trials, a frequency of $50 \mathrm{~Hz}$ has been recommended for patients with Stress Urinary Incontinence (SUI) and a frequency of $10-20 \mathrm{~Hz}$ for urge urinary incontinence (UUI). The device is applied transvaginally, and treatment sessions are run daily for a course of about 4-12 weeks and last about 15 to 30 minutes at the highest intensity that the patient is able to endure. Cure and clinical improvement rates vary between $60 \%$ and $80 \%$, and no harmful side effects have ever occurred [75-77]. Being a conservative treatment, TES is often recommended in cases of mild or moderate cases of UUI; in addition to this, new research has been suggested using TES also for treating FSD, but its efficacy still needs to be shown [78-80]. In this regard, Giuseppe et al. [81] evaluated 37 women with UUI (23 of them also suffering from FSDs) using a voiding diary and FSFI before and after three months of TES. The results of this study showed a significant improvement of sexual function in 
the 23 women with UUI and FSD after three months of TES [81]. Moreover, several studies underline the effectiveness of a combined rehabilitative approach for the treatment of FSDs associated with UUI, where electrical stimulation is applied together with biofeedback, pelvic floor muscle exercises, and vaginal cones $[82,83]$.

The mode of action of TES involves increasing the contraction of the sphincter on the urethra, and the strength of the PFMs to hold the pelvic structures [84].

The resulting muscle hypertrophy could also exert a passive mechanical pressure on the urethra, thus helping to improve symptoms in SUI. When PFMs are stimulated trough TES, the short bust of electricity could induce reflexes to induce the contraction of para- and peri-urethral muscles and the inhibition of the detrusor activity [85]. The inhibitory reflex also improves the bladder storage. To benefit from these effects, patients with UUI need to have an intact peripheral neuronal pathway to the PFMs [81].

For women in whom more conservative treatments fail, the next option is SN, the lowest invasive procedure that allows the avoidance or postponement of major interventions [70]. Tanagho and Schmidt were the first to report the use of this procedure in 1988, where the implant of an electrode in the S3-S4 sacral foramen allowing to provide ongoing stimuli to the sacral nerves, thus improving urinary symptoms [85]. During the procedure, an electrode is placed percutaneously via the S3 foramen, which provides low-amplitude electrical stimulation to the S3 nerve root and results in changes to bladder storage function $[86,87]$. The mechanism of action of SN is not fully understood. The most wellaccepted hypothesised mechanism is that the effects of SN derive from stimulation of the alpha myelinated afferent fibres and unmyelinated C fibres in the S3 and S4 pelvic and pudendal nerve roots that affect the micturition reflex $[87,88]$. Several studies have underlined that SN also affects the activity in the brain [70]. The resulting effect of central neuromodulation in several areas has been demonstrated with both positron emission tomography (PET) and functional magnetic resonance imaging (FMRI) [89].

Efficacy of SN has been demonstrated in literature in both short and long term [87]. Improvement in urinary symptoms from SN reported in case series and randomized ranges from $64 \%$ to $88 \%$ [70]. Refractory OAB symptoms can be improved by up to $50 \%$ with SN, as a few RCTs have shown [90-92].

Regarding sexual function of women treated with $\mathrm{SN}$, the data available in literature seem to highlight a positive effect of $\mathrm{SN}$ on sexual function of women with pelvic floor disorders, even if actual evidence is still insufficient to definitely confirm the effectiveness of this procedure for the treatment of FSDs $[93,94]$.

In conclusion, both TES and SN seem to be viable treatment options for patients with refractory overac- tive bladder. However, further studies are needed in order to better understand the effectiveness and limits of these therapies and their impact on quality of life, sexual function, and psychological well-being.

\section{Disclosure}

The authors report no conflict of interest.

\section{References}

1. Sultan AH, Monga A, Lee J, et al. An International Urogynecological Association (IUGA)/International Continence Society (ICS) joint report on the terminology for female anorectal dysfunction. Neurourol Urodyn 2017; 36: 10-34

2. Abrams P, Andersson KE, Birder L, et al. Fourth International Consultation on Incontinence Recommendations of the International Scientific Committee: Evaluation and treatment of urinary incontinence, pelvic organ prolapse, and fecal incontinence. Neurourol Urodyn 2010; 29: 213-240.

3. Abrams P. Describing bladder storage function: overactive bladder syndrome and detrusor overactivity. Urology 2003; 62: 28-37; discussion 40-42.

4. Patnaik SS, Laganà AS, Vitale SG, et al. Etiology, pathophysiology and biomarkers of interstitial cystitis/painful bladder syndrome. Arch Gynecol Obstet 2017; 295: 1341-1359.

5. Grundy L, Caldwell A, Brierley SM. Mechanisms Underlying Overactive Bladder and Interstitial Cystitis/Painful Bladder Syndrome. Front Neurosci 2018; 12: 931.

6. Laganà AS, La Rosa VL, Rapisarda AMC, et al. Pelvic organ prolapse: The impact on quality of life and psychological well-being. J Psychosom Obstet Gynecol 2018; 39: 164-166.

7. Kim MS, Lee GH, Na ED, et al. The association of pelvic organ prolapse severity and improvement in overactive bladder symptoms after surgery for pelvic organ prolapse. Obstet Gynecol Sci 2016; 59: 214-219.

8. Vercellini P, Bracco B, Mosconi P, et al. Norethindrone acetate or dienogest for the treatment of symptomatic endometriosis: a before and after study. Fertil Steril 2016; 105: 734-743.e3.

9. Vitale SG, La Rosa VL, Rapisarda AMC, et al. The Importance of a Multidisciplinary Approach or Women with Pelvic Organ Prolapse and Cystocele. Oman Med J 2017; 32: 263-264.

10. Digesu GA, Salvatore S, Chaliha C, et al. Do overactive bladder symptoms improve after repair of anterior vaginal wall prolapse? Int Urogynecol J Pelvic Floor Dysfunct 2007; 18: 1439-1443.

11. Vitale SG, Laganà AS, Noventa $M$, et al. Transvaginal Bilateral Sacrospinous Fixation after Second Recurrence of Vaginal Vault Prolapse: Efficacy and Impact on Quality of Life and Sexuality. Biomed Res Int 2018; 2018: 5727165.

12. Clemons JL, Aguilar VC, Tillinghast TA, et al. Patient satisfaction and changes in prolapse and urinary symptoms in women who were fitted successfully with a pessary for pelvic organ prolapse. Am J Obstet Gynecol 2004; 190: 1025-1029.

13. Vitale SG, Laganà AS, Gulino FA, et al. Prosthetic surgery versus native tissue repair of cystocele: literature review. Updates Surg 2016; 68: 325-329.

14. Laganà AS, Sapia F, Butticè $S$, et al. Comment on "efficacy and safety of skeletonized mesh implants for advanced pelvic organ prolapse: 12 month follow up". World J Urol 2016; 34: 1499-1500.

15. Vitale SG, Laganà AS, Rapisarda AMC. Letter to the editor: Comment on "Simultaneous treatment of anterior vaginal wall prolapse and stress urinary incontinence by using transobturator four arms polypropylene mesh". Investig Clin Urol 2016; 57: 150-151.

16. Ko YH, Song C-H, Choi JW, et al. Effect on Sexual Function of Patients and Patients' Spouses After Midurethral Sling Procedure for Stress Urinary Incontinence: A Prospective Single Center Study. Low Urin Tract Symptoms 2016; 8: 182-185.

17. Laganà AS, La Rosa VL, Rapisarda AMC, et al. Comment on: "Effect on Sexual Function of Patients and Patients' Spouses After Midurethal 
Sling Procedure for Stress Urinary Incontinence: A Prospective Single Center Study”. Low Urin Tract Symptoms 2017; 9: 62.

18. Koch M, Rauchenwald T, Kivaranovic D, et al. Association of uterine leio myoma and overactive bladder syndrome. Int J Gynaecol Obstet 2018; 142: 365-369.

19. Stewart EA, Cookson CL, Gandolfo RA, et al. Epidemiology of uterine fibroids: a systematic review. BJOG 2017; 124: 1501-1512.

20. Laganà AS, Vergara D, Favilli $A$, et al. Epigenetic and genetic landscape of uterine leiomyomas: a current view over a common gynecological disease. Arch Gynecol Obstet 2017; 296: 855-867.

21. Vitale SG, Sapia F, Rapisarda AMC, et al. Hysteroscopic Morcellation of Submucous Myomas: A Systematic Review. Biomed Res Int 2017; 2017: 6848250.

22. Hazewinkel MH, Sprangers MAG, van der Velden J, et al. Long-term cervical cancer survivors suffer from pelvic floor symptoms: a crosssectional matched cohort study. Gynecol Oncol 2010; 117: 281-286.

23. Axelsen SM, Bek KM, Petersen LK. Urodynamic and ultrasound characteristics of incontinence after radical hysterectomy. Neurourol Urodyn 2007; 26: 794-799.

24. Bellia A, Vitale SG, Laganà AS, et al. Feasibility and surgical outcomes of conventional and robot-assisted laparoscopy for early-stage ovarian cancer: a retrospective, multicenter analysis. Arch Gynecol Obstet 2016; 294: 615-622.

25. Rossetti D, Vitale SG, Gulino FA, et al. Concomitant chemoradiation treatment in selected Stage I endometrioid endometrial cancers. Eur J Gynaecol Oncol 2016; 37: 657-661.

26. Cignini P, Vitale SG, Laganà AS, et al. Preoperative work-up for definition of lymph node risk involvement in early stage endometrial cancer: 5-year follow-up. Updates Surg 2017; 69: 75-82.

27. Kruppa J, Kavvadias T, Amann S, et al. Short and long-term urodynamic and quality of life assessment after nerve sparing radical hysterectomy: a prospective pilot study. Eur J Obstet Gynecol Reprod Biol 2016; 201: 131-134.

28. Vitale SG, Capriglione S, Zito G, et al. Management of endometrial, ovarian and cervical cancer in the elderly: current approach to a challenging condition. Arch Gynecol Obstet 2019; 299: 299-315.

29. Bruno A, Laganà AS, Leonardi V, et al. Inside-out: the role of anger experience and expression in the development of postpartum mood disorders. J Matern Fetal Neonatal Med 2018; 31: 3033-3038.

30. Hullfish KL, Fenner DE, Sorser SA, et al. Postpartum depression, urge urinary incontinence, and overactive bladder syndrome: is there an association? Int Urogynecol J Pelvic Floor Dysfunct 2007; 18: 1121-1126.

31. Melville JL, Walker E, Katon W, et al. Prevalence of comorbid psychiatric illness and its impact on symptom perception, quality of life, and functional status in women with urinary incontinence. Am J Obstet Gynecol 2002; 187: 80-87.

32. Tadic SD, Holstege G, Griffiths DJ. The CNS and bladder dysfunction. F1000 Med Rep 2012; 4: 20.

33. Milsom I, Abrams P, Cardozo L, et al. How widespread are the symptoms of an overactive bladder and how are they managed? A populationbased prevalence study. BJU Int 2001; 87: 760-766.

34. Tubaro A. Defining overactive bladder: epidemiology and burden of disease. Urology 2004; 64: 2-6.

35. Vitale SG, Caruso S, Rapisarda AMC, et al. Isoflavones, calcium, vitamin $D$ and inulin improve quality of life, sexual function, body composition and metabolic parameters in menopausal women: Result from a prospective, randomized, placebo-controlled, parallel-group study. Prz Menopauzalny 2018; 17: 32-38.

36. Cianci A, Colacurci N, Paoletti AM, et al. Soy Isoflavones, Inulin, Calcium, and Vitamin D3 in post-menopausal hot flushes: An observational study. Clin Exp Obstet Gynecol 2015; 42: 743-745.

37. Chen Y, Yu W, Yang Y, et al. Association between overactive bladder and peri-menopause syndrome: a cross-sectional study of female physicians in China. Int Urol Nephrol 2015; 47: 743-749.

38. Zhu L, Cheng X, Sun J, et al. Association between Menopausal Symptoms and Overactive Bladder: A Cross-Sectional Questionnaire Survey in China. PLoS One 2015; 10: e0139599.

39. Hakimi S, Aminian E, Alizadeh Charandabi SM, et al. Risk factors of overactive bladder syndrome and its relation to sexual function in menopausal women. Urologia 2018; 85: 10-14.
40. Roxburgh C, Cook J, Dublin N. Anticholinergic drugs versus other medications for overactive bladder syndrome in adults. Cochrane Database Syst Rev 2007: CD003190.

41. Duthie JB, Vincent M, Herbison GP, et al. Botulinum toxin injections for adults with overactive bladder syndrome. Cochrane Database Syst Rev 2011: CD005493.

42. Coyne KS, Sexton CC, Irwin DE, et al. The impact of overactive bladder, incontinence and other lower urinary tract symptoms on quality of life, work productivity, sexuality and emotional well-being in men and women: results from the EPIC study. BJU Int 2008; 101: 1388-1395.

43. Abrams P, Kelleher CJ, Kerr LA, et al. Overactive bladder significantly affects quality of life. Am J Manag Care 2000; 6: S580-590.

44. Lee KS, Choo MS, Seo JT, et al. Impact of overactive bladder on quality of life and resource use: results from Korean Burden of Incontinence Study (KOBIS). Health Qual Life Outcomes 2015; 13: 89.

45. Oh S-J, Ku JH, Choo M-S, et al. Health-related quality of life and sexual function in women with stress urinary incontinence and overactive bladder. Int J Urol 2008; 15: 62-67; discussion 67.

46. Coyne KS, Margolis MK, Jumadilova Z, et al. Overactive bladder and women's sexual health: what is the impact? J Sex Med 2007; 4: 656666.

47. Juliato CRT, Melotti IGR, Junior LCS, et al. Does the Severity of Overactive Bladder Symptoms Correlate With Risk for Female Sexual Dysfunction? J Sex Med 2017; 14: 904-909.

48. Berman JR, Adhikari SP, Goldstein I. Anatomy and physiology of female sexual function and dysfunction: classification, evaluation and treatment options. Eur Urol 2000; 38: 20-29.

49. Vitale SG, Caruso S, Rapisarda AMC, et al. Biocompatible porcine dermis graft to treat severe cystocele: impact on quality of life and sexuality. Arch Gynecol Obstet 2016; 293: 125-131.

50. Caruso S, Bandiera S, Cavallaro A, et al. Quality of life and sexual changes after double transobturator tension-free approach to treat severe cystocele. Eur J Obstet Gynecol Reprod Biol 2010; 151: 106-109.

51. Laganà AS, La Rosa VL, Palumbo MA, et al. The impact of stress urinary incontinence on sexual function and quality of life. Gazz Medica Ital 2018; 177: 415-416.

52. Vitale SG, La Rosa VL, Rapisarda AMC, et al. Sexual life in women with stress urinary incontinence. Oman Med J 2017; 32: 174-175.

53. Yip SK, Chan A, Pang S, et al. The impact of urodynamic stress incontinence and detrusor overactivity on marital relationship and sexual function. Am J Obstet Gynecol 2003; 188: 1244-1248.

54. Zahariou A, Karamouti M, Tyligada E, et al. Sexual function in women with overactive bladder. Female Pelvic Med Reconstr Surg 2010; 16: 31-36.

55. Sen I, Onaran M, Tan MO, et al. Evaluation of sexual function in women with overactive bladder syndrome. Urol Int 2007; 78: 112-115.

56. Del Rosso A, Pace G, Di Pierro ED, et al. Impact of Overactive Bladder on Sexual Function in Women. Urol J 2011; 78: 200-202.

57. Rosen R, Brown C, Heiman J, et al. The Female Sexual Function Index (FSFI): a multidimensional self-report instrument for the assessment of female sexual function. J Sex Marital Ther 2000; 26: 191-208.

58. Cozzolino M, Magro-Malosso ER, Tofani L, et al. Evaluation of sexual function in women with deep infiltrating endometriosis. Sex Reprod Healthc 2018; 16: 6-9.

59. Zomkowski K, Toryi AM, Sacomori C, et al. Sexual function and quality of life in gynecological cancer pre- and post-short-term brachytherapy: a prospective study. Arch Gynecol Obstet 2016; 294: 833-840.

60. Caruso S, Cianci S, Vitale SG, et al. Sexual function and quality of life of women adopting the levonorgestrel-releasing intrauterine system (LNG-IUS $13.5 \mathrm{mg}$ ) after abortion for unintended pregnancy. Eur J Contracept Reprod Health Care 2018; 23: 24-31.

61. Mollaioli D, Lin L-T, Shah M, et al. Multidisciplinary management of sexual quality of life among menopausal women with urogynecological complains. Ital J Gynaecol Obstet 2018; 30: 15-20.

62. La Rosa VL, Sapia F, Salvaggio C, et al. Quality of life and sexual function in women with genitourinary syndrome of menopause (GSM): effectiveness of local therapy with ultralow-concentration estriol vaginal gel. Ital J Gynaecol Obstet 2018; 30: 7-13.

63. Caruso S, Cianci S, Vitale SG, et al. Effects of ultralow topical estriol dose on vaginal health and quality of life in postmenopausal women who underwent surgical treatment for pelvic organ prolapse. Menopause 2017; 24: 900-907. 
64. Laganà AS, Vitale SG, Stojanovska L, et al. Preliminary results of a singlearm pilot study to assess the safety and efficacy of visnadine, prenylflavonoids and bovine colostrum in postmenopausal sexually active women affected by vulvovaginal atrophy. Maturitas 2018; 109: 78-80.

65. Klutke CG, Burgio KL, Wyman JF, et al. Combined effects of behavioral intervention and tolterodine in patients dissatisfied with overactive bladder medication. J Urol 2009; 181: 2599-2607.

66. Bartley JM, Blum ES, Sirls LT, et al. Understanding clinic options for overactive bladder. Curr Urol Rep 2013; 14: 541-548.

67. Olivera CK, Meriwether K, El-Nashar S, et al. Nonantimuscarinic treatment for overactive bladder: a systematic review. Am J Obstet Gyneco 2016; 215: 34-57

68. Sears CLG, Lewis C, Noel K, et al. Overactive bladder medication adherence when medication is free to patients. J Urol 2010; 183: 1077-1081.

69. Kurpad R, Kennelly MJ. The evaluation and management of refractory neurogenic overactive bladder. Curr Urol Rep 2014; 15: 444.

70. Laviana A, Jellison F, Kim J-H. Sacral neuromodulation for refractory overactive bladder, interstitial cystitis, and painful bladder syndrome. Neurosurg Clin N Am 2014; 25: 33-46.

71. Fossberg E, Sørensen S, Ruutu M, et al. Maximal electrical stimulation in the treatment of unstable detrusor and urge incontinence. Eur Urol 1990; 18: 120-123.

72. Yamanishi T, Yasuda K, Sakakibara R, et al. Randomized, double-blind study of electrical stimulation for urinary incontinence due to detrusor overactivity. Urology 2000; 55: 353-357.

73. Monga AK, Tracey MR, Subbaroyan J. A systematic review of clinical studies of electrical stimulation for treatment of lower urinary tract dysfunction. Int Urogynecol J 2012; 23: 993-1005.

74. Schmidt AP, Sanches PRS, Silva DP, et al. A new pelvic muscle traine for the treatment of urinary incontinence. Int J Gynaecol Obstet 2009; 105: 218-222.

75. Berghmans LC, Hendriks HJ, De Bie RA, et al. Conservative treatment of urge urinary incontinence in women: a systematic review of randomized clinical trials. BJU Int 2000; 85: 254-263.

76. Alves PGJM, Nunes FR, Guirro ECO. Comparison between two different neuromuscular electrical stimulation protocols for the treatment of female stress urinary incontinence: a randomized controlled trial. Rev Bras Fisioter 2011; 15: 393-398.

77. Castro RA, Arruda RM, Zanetti MRD, et al. Single-blind, randomized, controlled trial of pelvic floor muscle training, electrical stimulation, vaginal cones, and no active treatment in the management of stress urinary incontinence. Clinics (Sao Paulo) 2008; 63: 465-472.

78. Seo JT, Choe JH, Lee WS, et al. Efficacy of functional electrical stimulation-biofeedback with sexual cognitive-behavioral therapy as treatment of vaginismus. Urology 2005; 66: 77-81.

79. Rosenbaum TY. Physiotherapy treatment of sexual pain disorders. J Sex Marital Ther 2005; 31: 329-340.

80. Amaro JL, Oliveira Gameiro MO, Padovani CR. Treatment of urinary stress incontinence by intravaginal electrical stimulation and pelvic floor physiotherapy. Int Urogynecol J Pelvic Floor Dysfunct 2003; 14: 204-208; discussion 208.

81. Giuseppe PG, Pace G, Vicentini C. Sexual function in women with urinary incontinence treated by pelvic floor transvaginal electrical stimulation. J Sex Med 2007; 4: 702-707.

82. Rivalta M, Sighinolfi MC, De Stefani S, et al. Biofeedback, electrical stimulation, pelvic floor muscle exercises, and vaginal cones: a combined rehabilitative approach for sexual dysfunction associated with urinary incontinence. J Sex Med 2009; 6: 1674-1677.

83. Rivalta M, Sighinolfi MC, Micali S, De Stefani S, Bianchi G. Sexual func tion and quality of life in women with urinary incontinence treated by a complete pelvic floor rehabilitation program (biofeedback, functional electrical stimulation, pelvic floor muscles exercises, and vaginal cones) J Sex Med 2010; 7: 1200-1208.

84. Amaro JL, Gameiro MO, Padovani CR. Effect of intravaginal electrical stimulation on pelvic floor muscle strength. Int Urogynecol J Pelvic Floor Dysfunct 2005; 16: 355-358.

85. Tanagho EA, Schmidt RA. Electrical stimulation in the clinical management of the neurogenic bladder. J Urol 1988; 140: 1331-1339.

86. Bartley J, Gilleran J, Peters K. Neuromodulation for overactive bladder Nat Rev Urol 2013; 10: 513-521.
87. Sukhu T, Kennelly MJ, Kurpad R. Sacral neuromodulation in overactive bladder: a review and current perspectives. Res Reports Urol 2016; 8: 193-199.

88. Leng WW, Chancellor MB. How sacral nerve stimulation neuromodulation works. Urol Clin North Am 2005; 32: 11-18.

89. Tadic SD, Griffiths D, Schaefer W, et al. Brain activity underlying impaired continence control in older women with overactive bladder. Neurourol Urodyn 2012; 31: 652-658.

90. Latini JM, Alipour M, Kreder KJ. Efficacy of sacral neuromodulation for symptomatic treatment of refractory urinary urge incontinence. Urology 2006; 67: 550-553; discussion 553-554.

91. Hassouna MM, Siegel SW, Nÿeholt AA, et al. Sacral neuromodulation in the treatment of urgency-frequency symptoms: a multicenter study on efficacy and safety. J Urol 2000; 163: 1849-1854.

92. Schmidt RA, Jonas U, Oleson KA, et al. Sacral nerve stimulation for treatment of refractory urinary urge incontinence. Sacral Nerve Stimulation Study Group. J Urol 1999; 162: 352-357.

93. Lombardi G, Finazzi Agrò E, Del Popolo G. Sacral neuromodulation and female sexuality. Int Urogynecol J 2015; 26: 1751-1757.

94. Khunda A, McCormick C, Ballard P. Sacral neuromodulation and sexual function: a systematic review and meta-analysis of the literature. Int Urogynecol J 2019; 30: 339-352 